\title{
Research Paper: Effectiveness of Family-Based Early Intervention on the Degree of Joint Attention (Responding) of the Children with Autism Spectrum Disorder: A Single-Subject Study
}

\author{
*Nahid Vakilizadeh ${ }^{1}$, Ahmad Abedi ${ }^{1}$, Alireza Mohseni Ezhiyeh ${ }^{1}$, Elnaz Pishghadam² \\ 1. Department of Children with Special Needs, Faculty of Psychologic and Education Science, University of Isfahan, Isfahan, Iran. \\ 2. Department of Consulting, Faculty of Psychologic and Education Science, University of Isfahan, Isfahan, Iran.
}

Citation: Vakilizadeh N, Abedi A, Mohseni Ezhiyeh AR, Pishghadam E. [Effectiveness of family-based early intervention on the degree of joint attention (responding) of the children with autism spectrum disorder: A single-subject study (Persian)]. Journal of Rehabiltation. 2016; 17(1):42-53. http://dx.doi.org/10.20286/jrehab-170140

dol: : http://dx.doi.org/10.20286/jrehab-170140

Received: 5 Aug. 2015 Accepted: 9 Des. 2015
Keywords: Autistic disorder, Joint attention, Early intervention, Child preschoo

\section{ABSTRACT}

Objective Joint attention refers to person's ability in focusing on the present information in his or her visual attention, along with existing information on other's visual attention. In this process, 2 people actively pay attention to a thing, situation, or event. Defects in joint attention is considered one of the first diagnosable signs in children with autism spectrum disorder (ASD). This skill has considerable effect on growth and development of social, cognitive, and verbal skills. In other words, joint attention may act as a key skill, i.e. achieving this area of growth, brings several by-products for children. Therefore, using therapeutic early interventions in order to improve the joint attention of children with ASD is necessary. The present study aimed to investigate the effectiveness of family-based early intervention on the improvement of joint attention of the children with ASD.

Materials \& Methods The research population included 57 children who had referred to Ordibehesht Autism Center in Isfahan. Because the present research sought for special cases, the purposeful sampling method was used. In this regard, the research sample comprised 3 children of 3-5 years old who had symptoms of autism spectrum disorder by the diagnosis of specialists, and had difficulties regarding joint attention. The research instrument was the Gilliam Autism Rating Scale (GARS) and Early Social Communication Scales (ESCS). In the present study, the single-subject study with the A-B design was used. In this method, after 5 baseline sessions, intervention was started and during 12 individual sessions, the joint attention skill is taught to children. To analyze the obtained data, at first the raw data were converted to standard T scores and the situation of baseline, intervention, and follow up of every subject was drawn on the diagram. To interpret and infer from the diagrams, we used visual analyses, trending, and stability, as well as percentages of non-overlapping data and overlapping data.

Results According to the visual analyses of the data diagrams, the intervention was effective on the 3 subjects. The mean scores of 3 subjects in the baseline have increased from 39.92, 37.30, and 38.89 to $52.04,52.79$, and 51.69, respectively. The percentage of non-overlapping data (PND) in the two baseline and intervention situations for the 3 subjects was $83 \%, 100 \%$, and $91 \%$. This effectiveness was observable in the follow-up stage.

Conclusion The findings of the present study indicated that the family-based early intervention can be an effective educational program for improvement of joint attention of the preschool children with ASD. Because defects in joint attention is one of the main features of children with ASD and joint attention brings improvement in other aspects of growth, we suggest that improving joint attention be considered as a main objective in rehabilitation and educational interventions in children with autism.

\section{* Corresponding Author:}

Nahid Vakilizadeh, MSc.

Address: Department of Children with Special Needs, Faculty of Psychologic and Education Science, University of Isfahan, Hezar Jarib St., Azadi Sq., Isfahan, Iran. Tel: +98 (916) 2388155

E-Mail: nahid.v1991@gmail.com 


\title{
اثربخشى مداخله زودهنكام مبتنىبر والدين بر ميزان توجه اشتراكى (ياسخدهى) كودكان

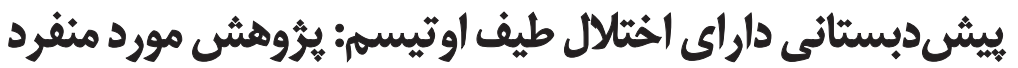

\author{
"ناهيد وكيلىزاده'، احمد عابدى'، عليرضا محسنى ازئي'، الناز بيشقدم'

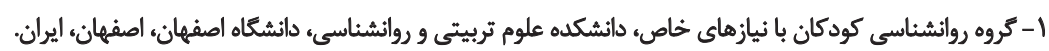 \\ r- كروه مشاوره، دانشكده علوم تربيتى و روانشناسى، دانشكاه اصفهان، اصفهاني، ايران.
}

\begin{abstract}
حكبl

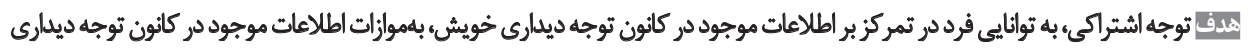

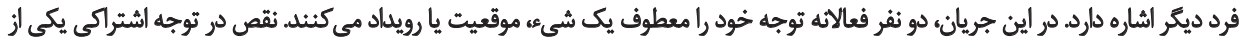

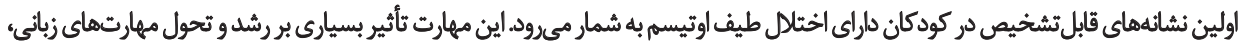

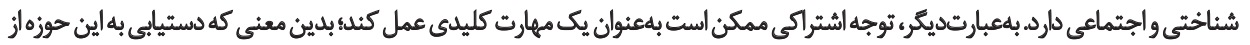

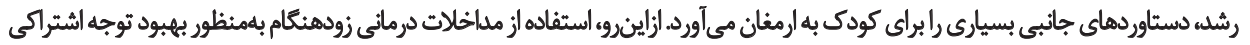

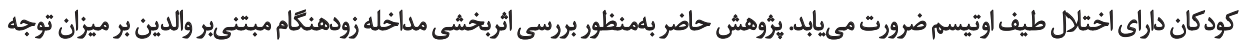

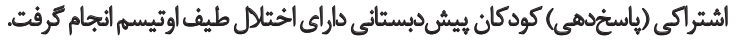

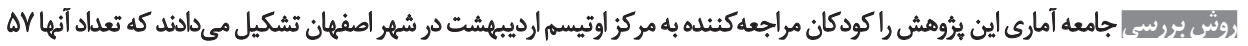

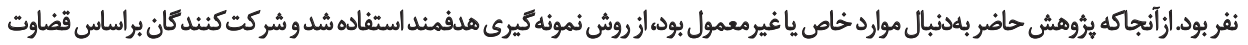

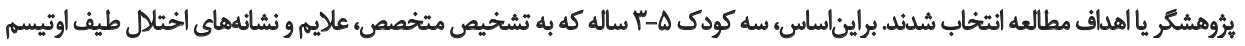

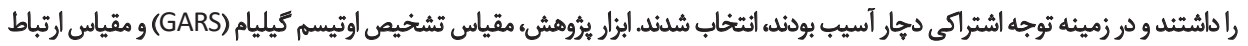

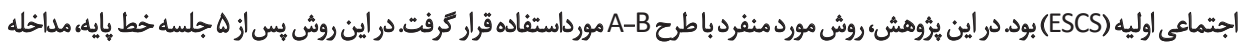

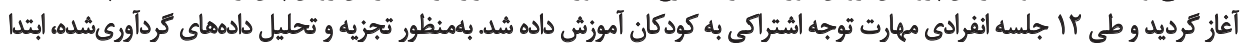

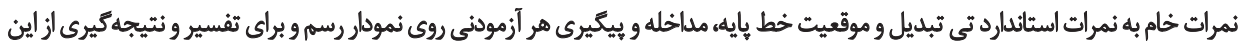

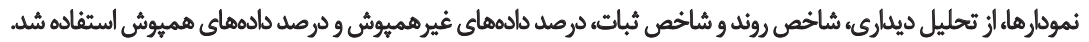

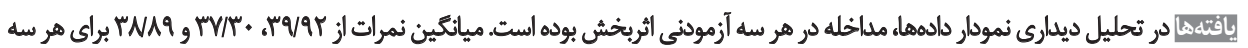

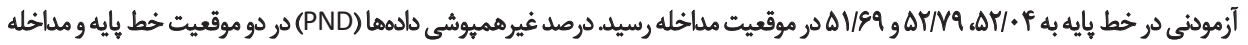

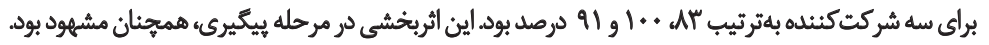

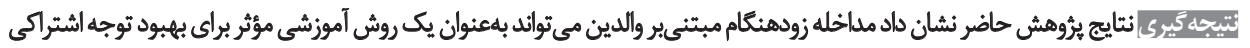

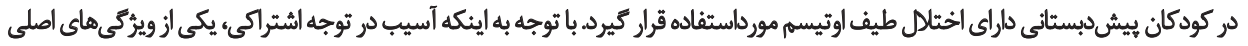

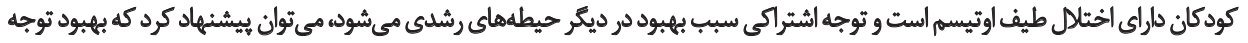

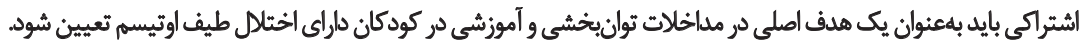

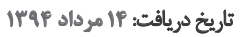

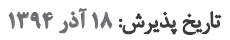

كليدواؤهها: - ن

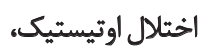
توجهه اشتراكيء مدانحليه زودهنكام، كودكان

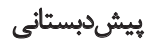

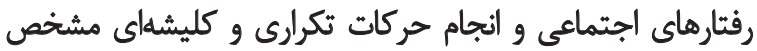
مقلمه

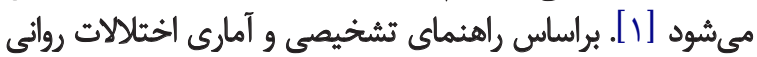
(DSM-IV)

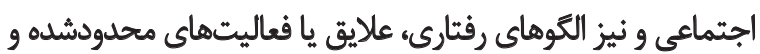

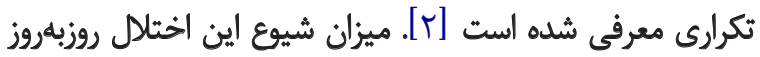

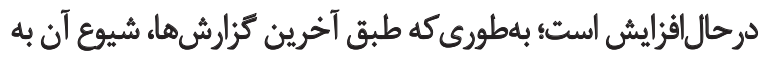

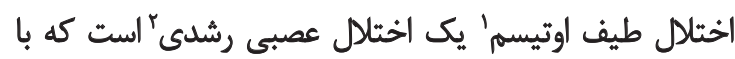

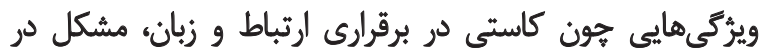

1. Autism spectrum disorder

2. Neurodevelopmental disorder

\section{-}


جدول ا. مراحل آموزش توجه اشتراكى (ياسخدهى).

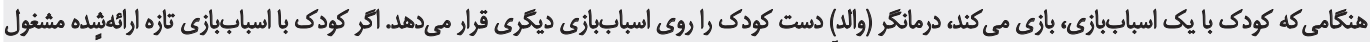

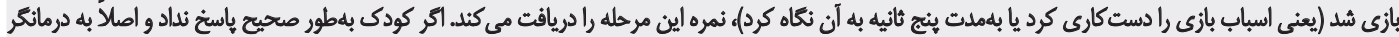

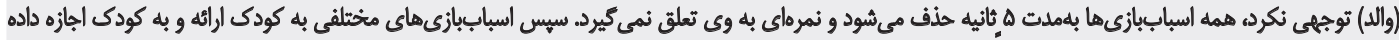

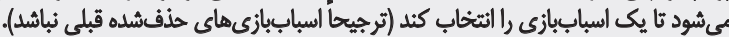

مرحله اول

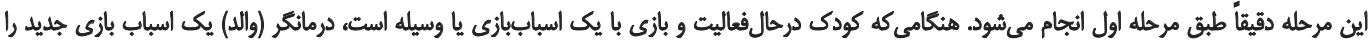

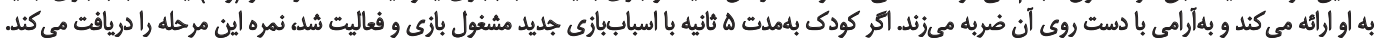

مرحلd دوم

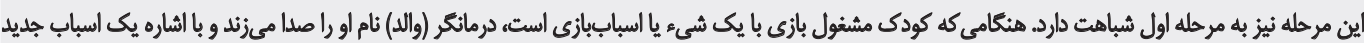

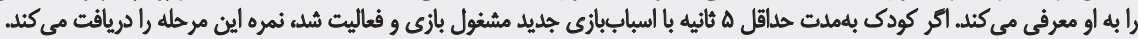

مرحله سوم

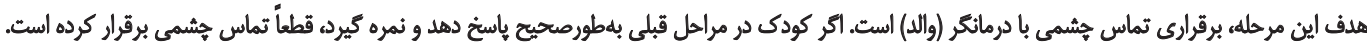

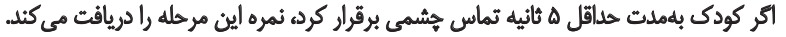

مرحله جهارم

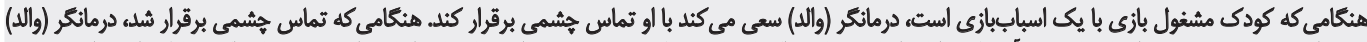

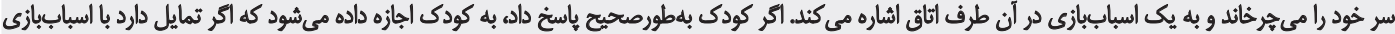

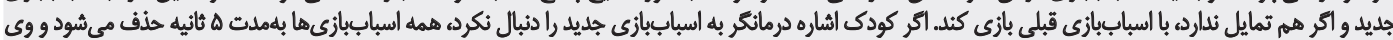

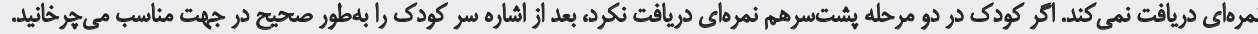

مرحله ينجمه

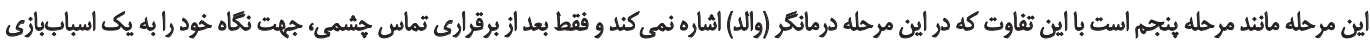

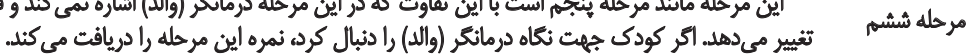

توانبخنتى

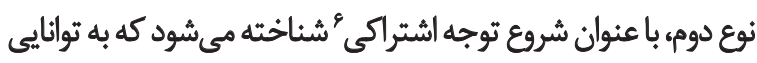

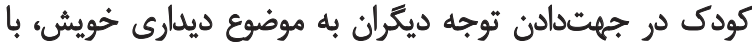

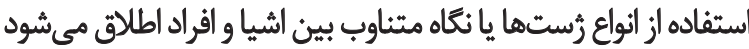

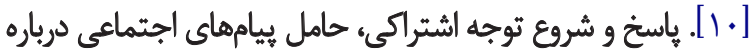

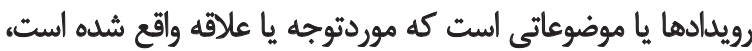

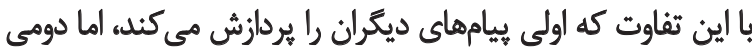

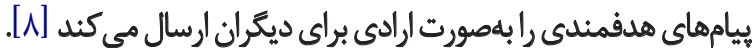

اهميت توجه اشتراكى در اين است كه آسيب در اين حوزه

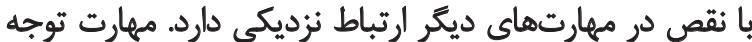

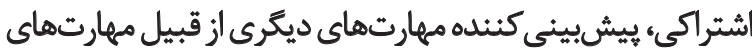

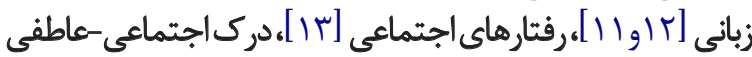

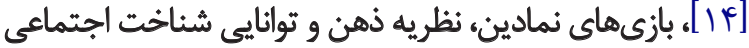

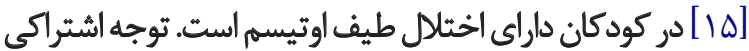

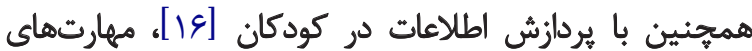

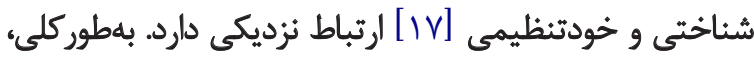

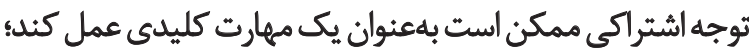

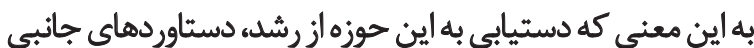

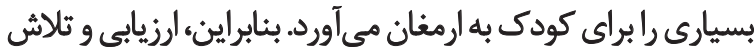

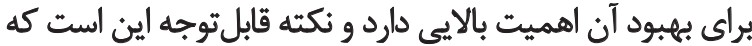

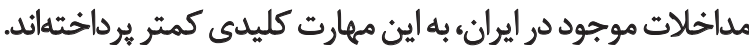

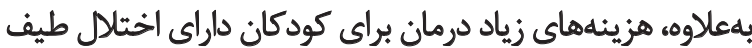

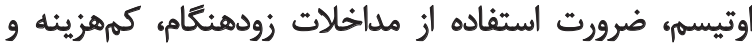
مبتنىبر والدين رابيشازيشيش آشكار مىنمايد.

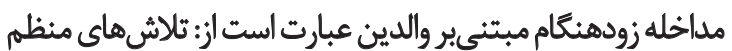
و مستمر بلواسطه مراقبان اصلى براى كمك بهنينكام به كودكان

6. Initiating Joint Attention (IJA)

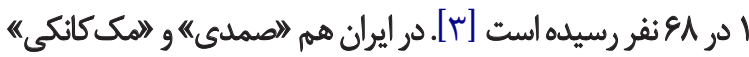

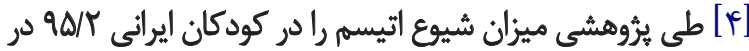

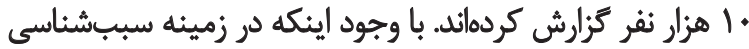

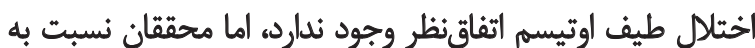
آسيبهاى روانشناختى اين اختلال در كودكان أكاهند.

يكى از آسيبهاي اساسى در كودكان داراي اختلال طيف اوتيسم، إنياء

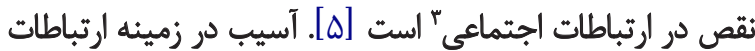

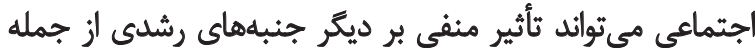

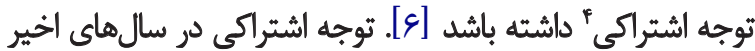

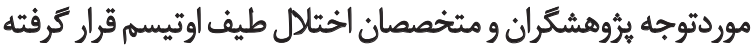

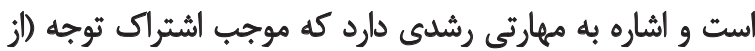

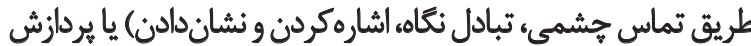

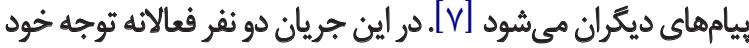

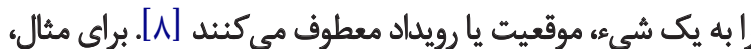

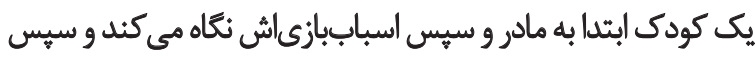
مي كوشد مادرش را متوجه آن كند.

محتقان با استفاده از فيلمبردارى ويديويى از دوران رشد كودكان،

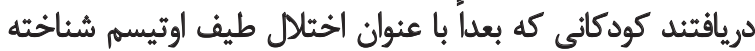

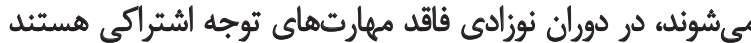

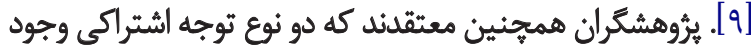

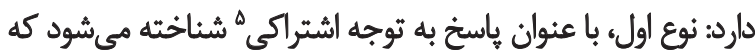

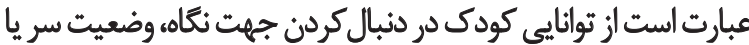

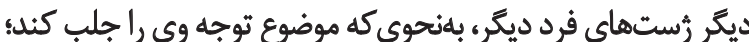

3. Social communication

4. Joint attention

5. Responding to Joint Attention (RJA) 
زودهنكام مبتنى بير والدين بر ميزان توجه اشتراكى (ياسخدهى) در كودكان بيشدبشتانى داراى اختلال طيف اوتيسم انجام شد.

\section{ووشٌ بروسي}

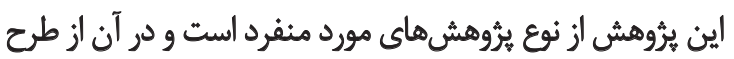

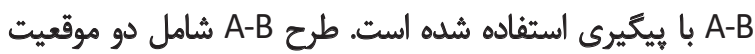

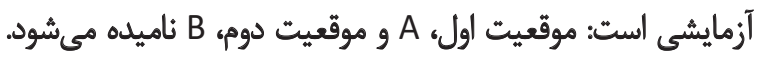

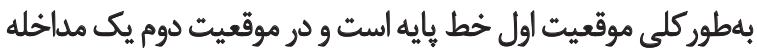

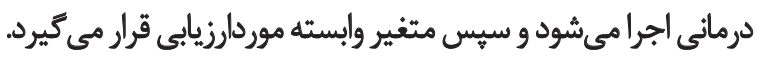

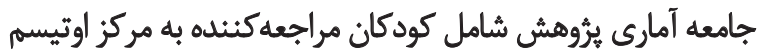

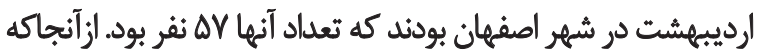

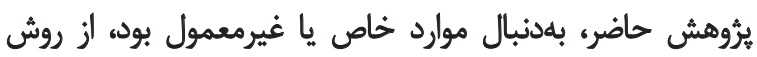

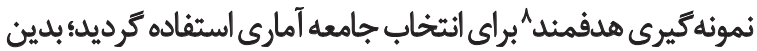

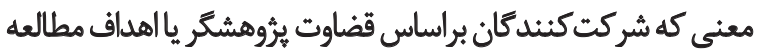

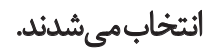

\section{معيارهاي ورودو وخروج كودكان به مطالعه}

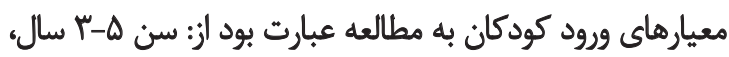

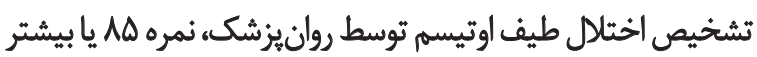

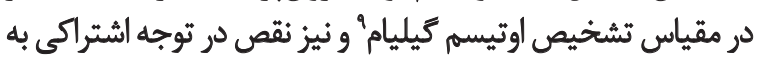

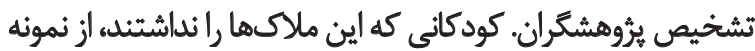
حذف شدند.

ملاكهاى خروج كه موجب حذف برخي از آزمودنىها شده،

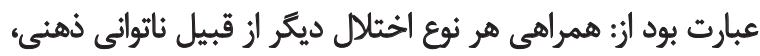

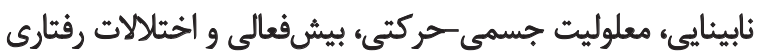

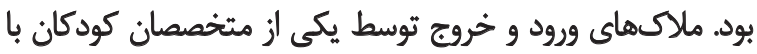

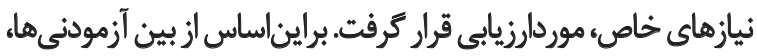

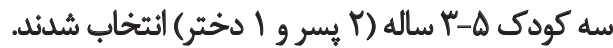

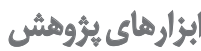

در اين يُروهش بهمنظور تشخيص اختلال طيف اوتيسم علاوهبر نظر

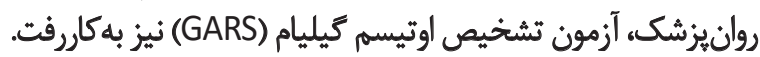

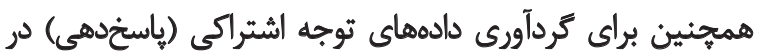

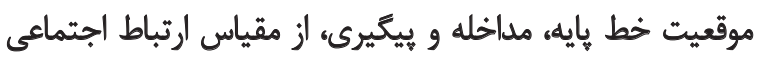

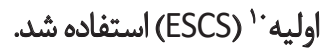

مقياس تشخيص اوتيسم كيليام (GARS)

اين مقياس در سال 1990 توسط "كيليامه طراحي شده است

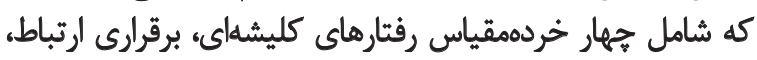

8. Purposeful sampling

9. Gilliam Autism Rating Scale (GARS)

10. Early Social Communication Scales (ESCS)
زير ه سال كه از نظر رشدى آسيبذيذير و ناتوان هستند [1 إ]

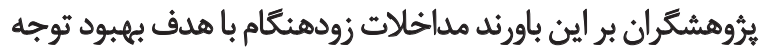

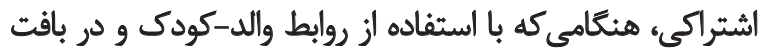

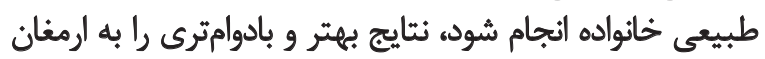

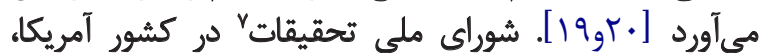

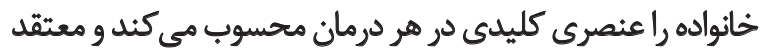

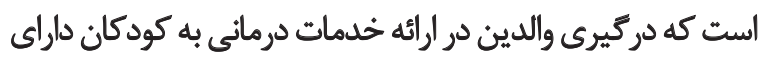

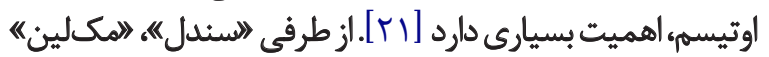

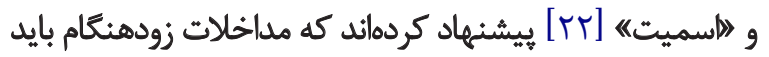

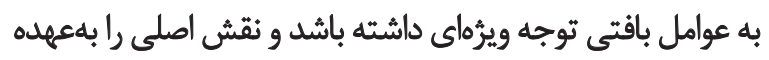

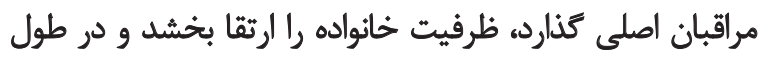

فعاليتهاى روزمره در محيطهاى طبيعى خانواني خانه انجام كيرد.

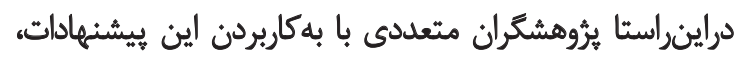

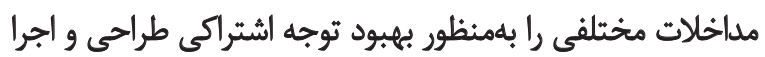

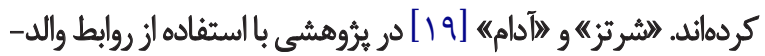

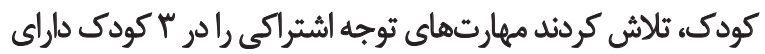

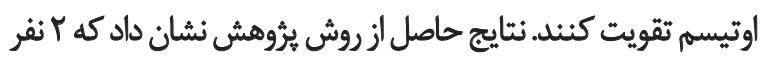

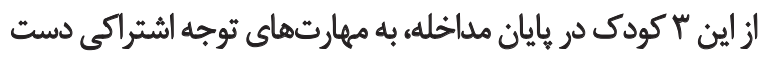

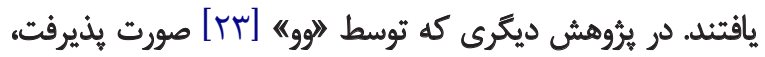

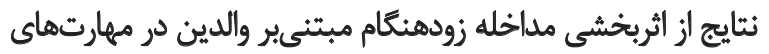
توجه اشتراكى كودكان داراى اختلال طيف اوتيسه حكايت داشت دائت

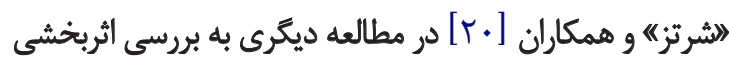

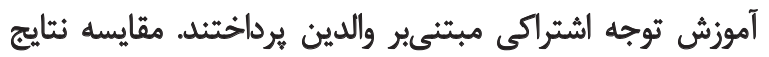

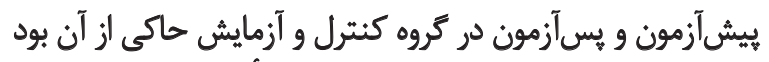

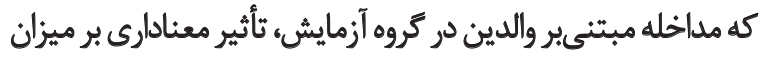

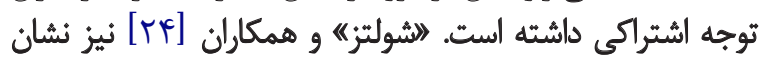

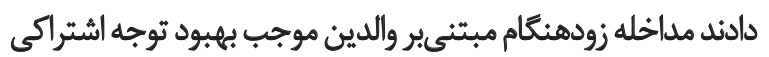

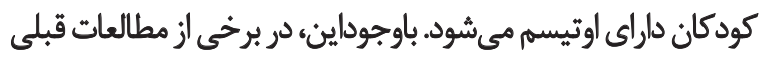

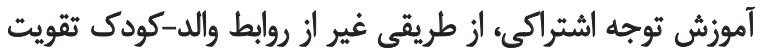

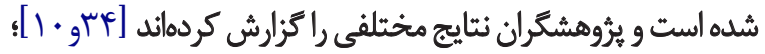

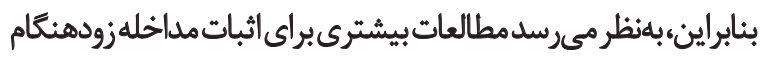

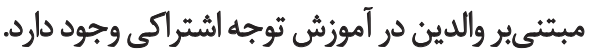

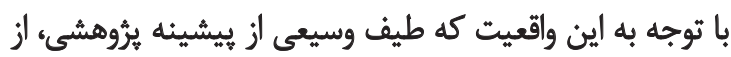

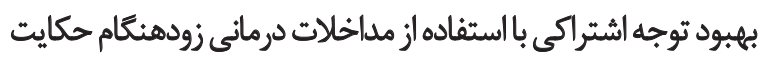

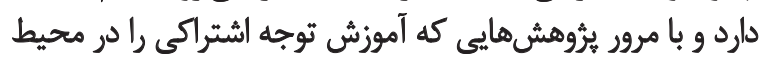

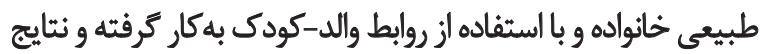

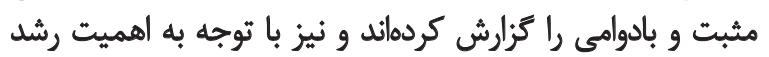

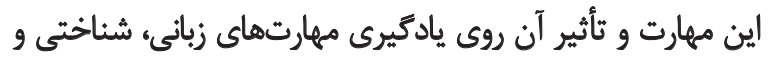

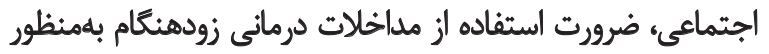

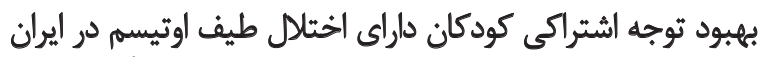

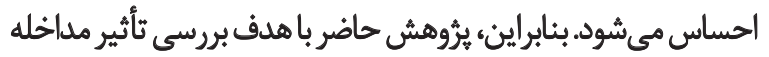

7. National research council 
جدول ب. نمرات توجه اشتراكى (ياسخدهى) در موقعيت خط بايه براى هر سه شركت كنئده.

\begin{tabular}{|c|c|c|c|c|c|}
\hline \multicolumn{5}{|c|}{ جلسات خط يايه (A) } & \multirow{2}{*}{ - زمودنى } \\
\hline$\Delta$ & r & $r$ & $r$ & 1 & \\
\hline ra/ar & एव/q & एव/qr & ra/qu & ra/qr & كودك 1 \\
\hline YNA & re/NF & TE/TF & $r g / N F$ & $r g / \mu \varphi$ & كودك r \\
\hline PNAq & rNAq & TNAq & rNAq & rNAq & كودك بr \\
\hline
\end{tabular}

توانبخنتى

\section{جلسات أموزشى (أموزش ياسخدهى)}

در يرؤشش حاضر، جلسات آموزش توجه اشتراكى (ياستخدهى)، از

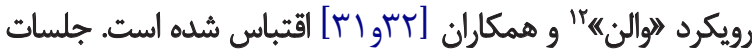

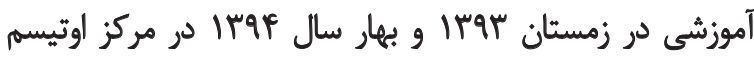

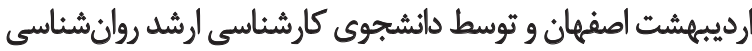

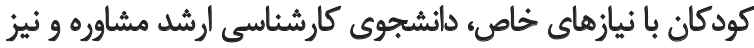
يكى ازٔ مربيان آن مركز انجام كرفت.

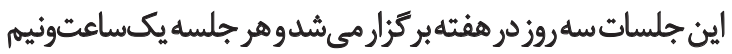

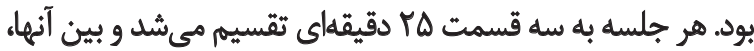
كودك ينج دقيقه فرصت استراحت داشت. تصاوير مختلفى روى دئ ديوار

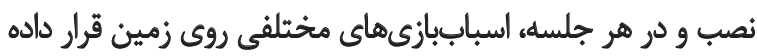

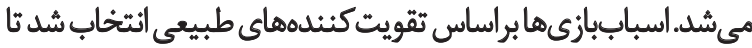
از تحريك كودى براى بازى اطميئان حاصل شود.

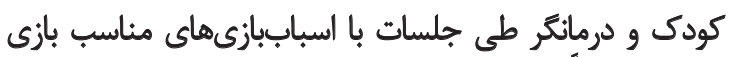

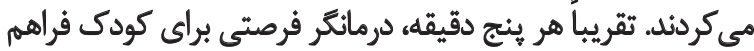

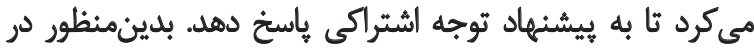

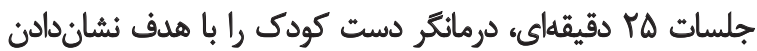

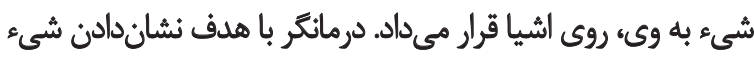

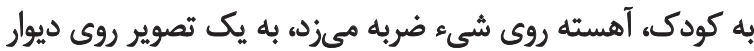

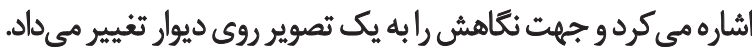

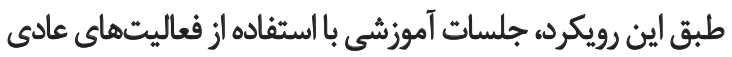

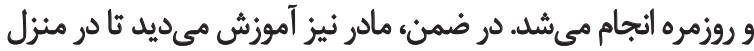

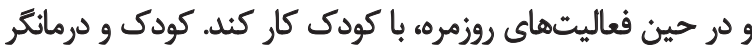

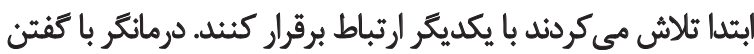

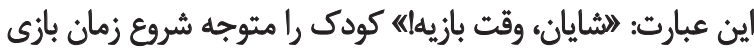

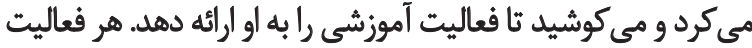

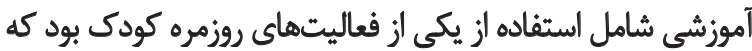

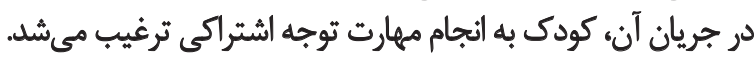

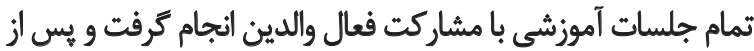

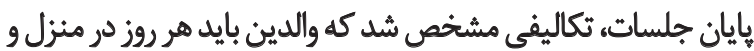
در حين تعاملات روزمره با كودى خود انجام دهند
تعاملات اجتماعى و اختلالات رشدى و Fr آيتم است. نمرهكذارى

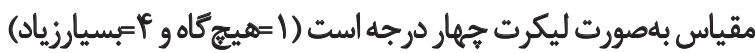

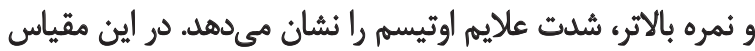

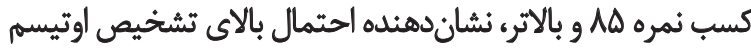

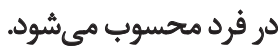

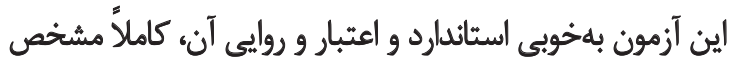

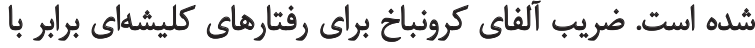

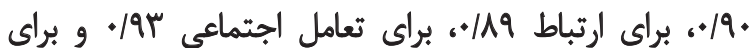

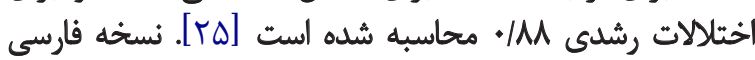

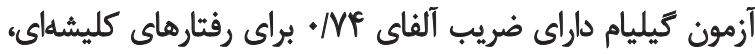

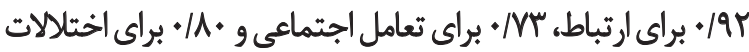

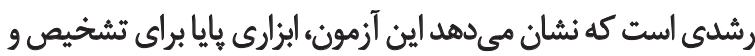

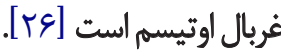

$$
\text { مثياس ارتباط اجتماعى اوليه (ESCS) }
$$

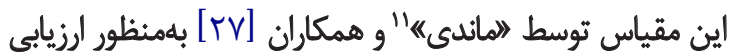

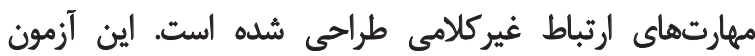

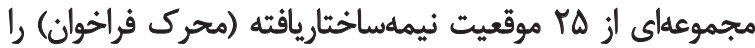

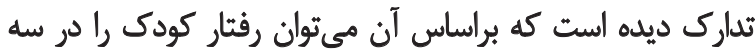

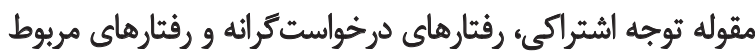

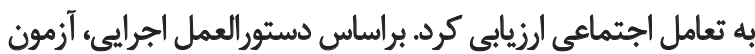

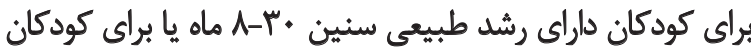

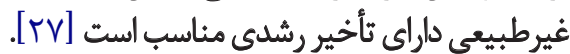

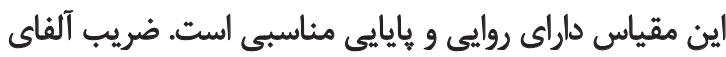

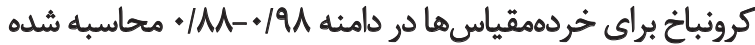

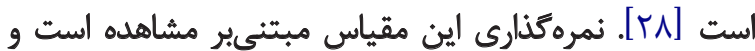

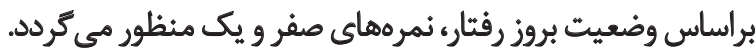

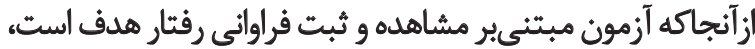

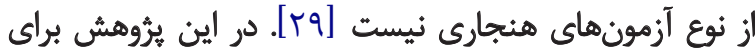

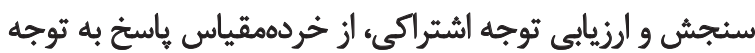

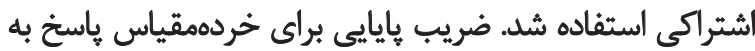

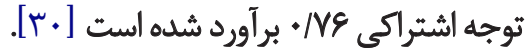


اين كار باعث شد كه كودى احساس خستكى نكند و علاقهمند به

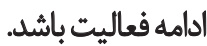

همجينين بيشنهاد شده است كه براى افزايش احتمال تعميمدهى

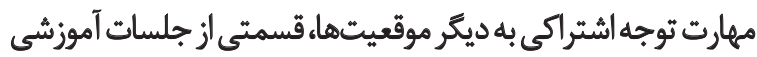

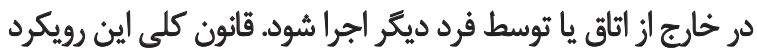

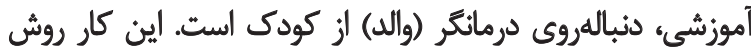

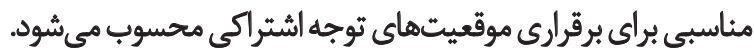

روش تجزيه و تحليل دادهها

بهمنظور تجزيه و تحليل دادههاى تردآورىشده، ابتدا نمرات خام

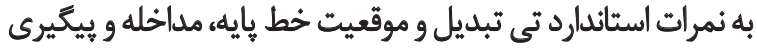

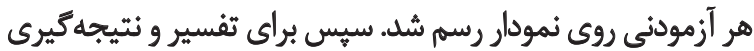

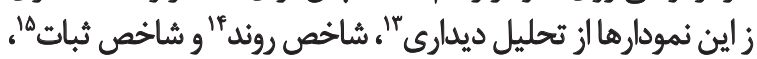

13.Visual analysis

14.Trending

15. Stability

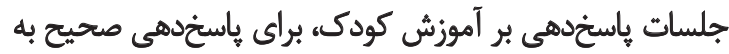

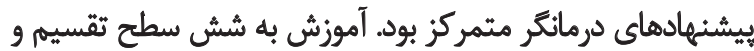

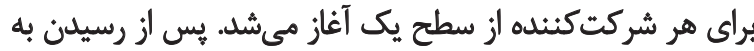

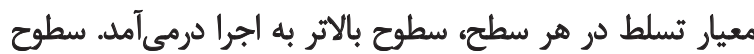

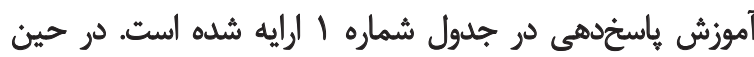

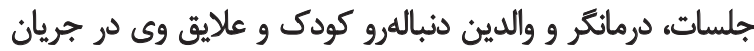

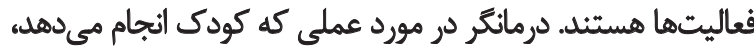

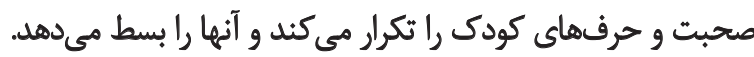

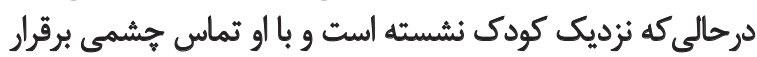

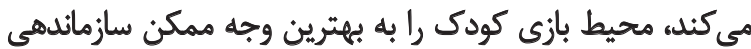

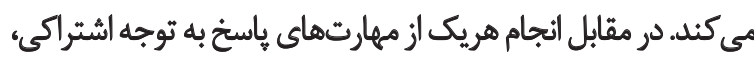

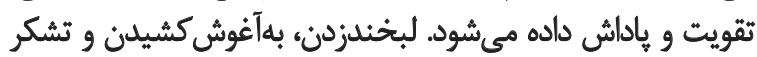
كرم كلامي از آن جملهاند.

بdطوركلى، انجام فعاليتهاى توجه اشتراكى با استفاده از بازىها

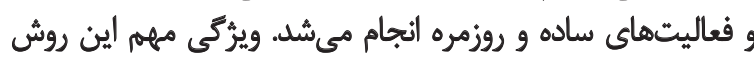

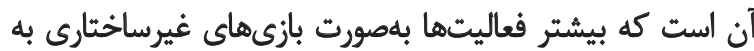

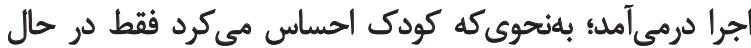
بازي كردن است، اما درمائكر و والدين در حال آمودئ آموزش به كودى بودند.

جدول با. نمرات توجه اشتراكى (ياسخدهى) در موقعيت مداخله و بيعيرى براى هر سه شركتكنئده.

\begin{tabular}{|c|c|c|c|c|c|c|c|c|c|c|c|c|c|c|c|}
\hline \multicolumn{3}{|c|}{ ييكيرى } & \multicolumn{12}{|c|}{ جلساث مداخله (B) } & \multirow{2}{*}{ أزمودنى } \\
\hline r & $r$ & 1 & $\pi$ & 11 & 1. & 9 & $\wedge$ & $\gamma$ & 8 & $\Delta$ & $r$ & r & r & 1 & \\
\hline$\Delta V / T \Delta$ & $\Delta V / T \Delta$ & $8+198$ & sapr & STM & $g r / M$ & $8+198$ & $\Delta T / 19$ & $\Delta . / \pi \%$ & PNFA & eq/ar & $\Delta \cdot / \pi T^{6}$ & HI/PV & TNIE & rq/ar & كودى 1 \\
\hline gr/PV & gr/gr & ge/ge & $8 \cdot \pi$ & gr/PY & $\Delta \Delta / q \vee$ & $\Delta r / A$. & $\Delta T / \Lambda_{0}$ & $9 / \Delta 1$ & $p q / \notin \varepsilon$ & $\Delta r / A$. & $F A / I T$ & $\Delta 1 / 9 T$ & $r Y / Q \Delta$ & $r=/ V A$ & كودى r \\
\hline DVदC & sinr & ST/A) & sim & QQ/8S & $9 / 11$ & $\Delta V / T \Delta$ & $\Delta V / \Delta A$ & $\Delta r / M T$ & $\Delta V / \Delta A$ & pqry & $F A / I T$ & $r . / 9 V$ & $r+/ 9 v$ & rNAq & كودى" \\
\hline
\end{tabular}

توانبخنى

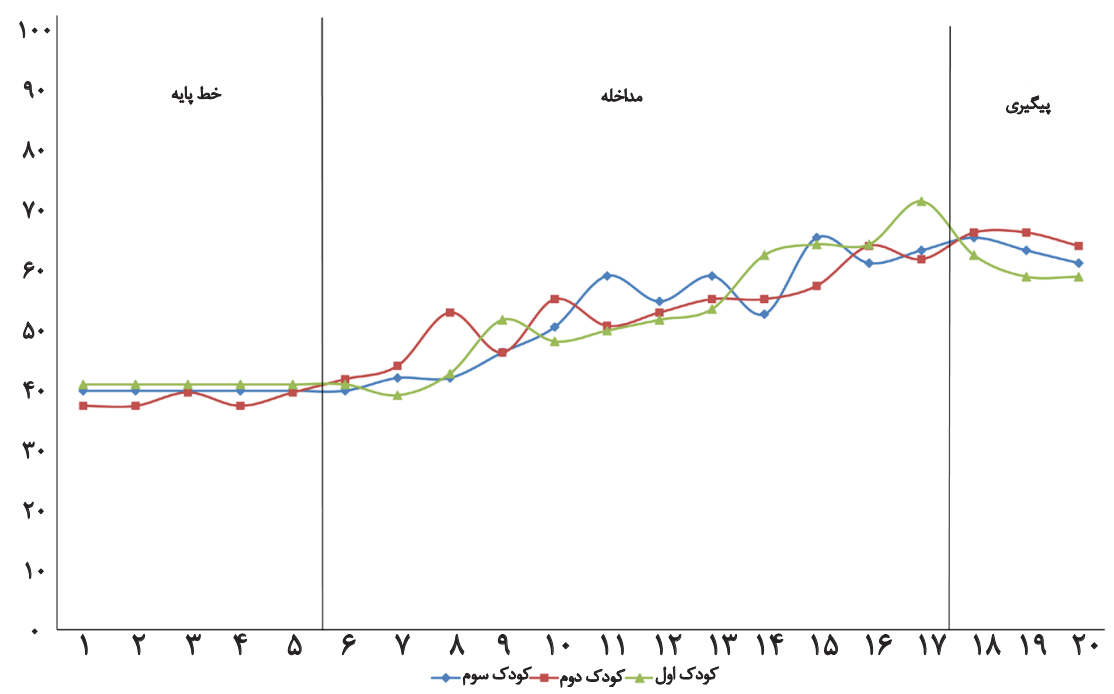




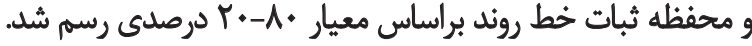

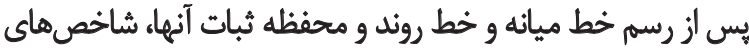

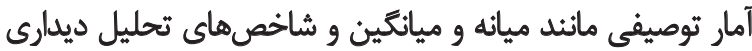

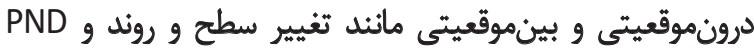

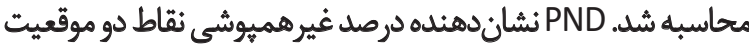

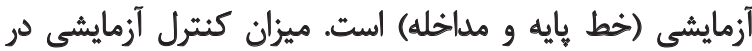

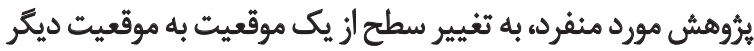

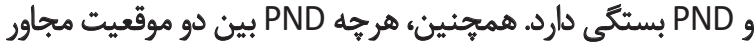
بالاتر باشد، با اطمينان بيشترى مى توان مداخله را اثربخش دانست.

\section{نتايج بلدستأمده براى شركت كثنده اول}

براساس تحليل ديدارى نمودار دادههاى شركت دكنيده اول، خط

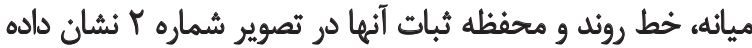

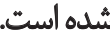

جدول شماره Fا، نتايج تحليل ديدارى درونموقعيتى و

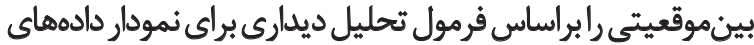

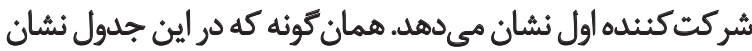

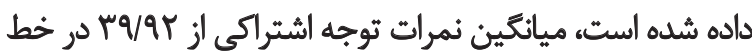

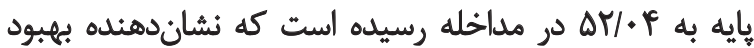
توجه اشتراكى (ياسخدهي) براى شركت كنينده موردنظر استه

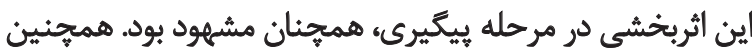

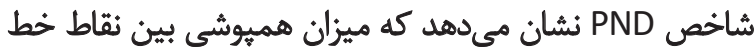

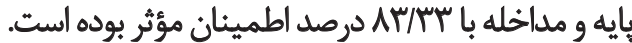

\section{نثايج بهدستآمده براي شركت كثنده دوم}

براساس تحليل ديدارى نمودار دادههاى شركت شئنده دوم، خط

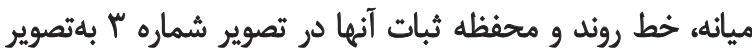

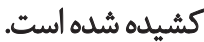

جدول شماره ه، نتايج تحليل ديدارى درونموقعيتى و

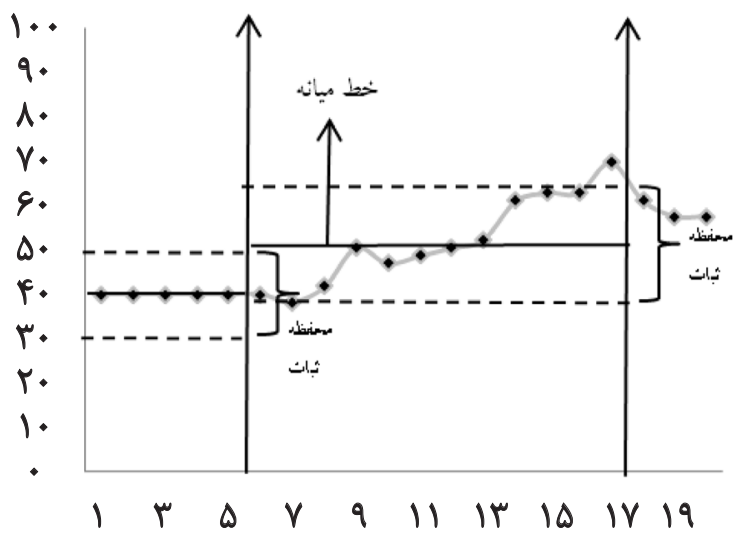

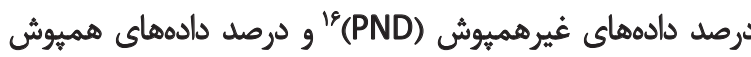
(POD)

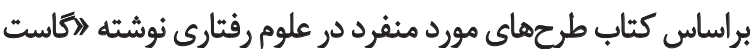

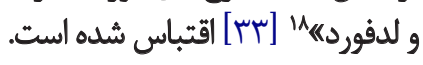

يافتهما

بامنظور خلاصهكردن نتايج بهدست آمده، هريك از جلسات خط

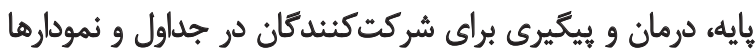

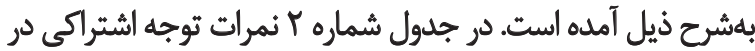

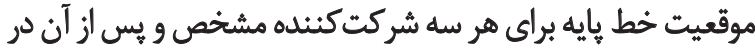

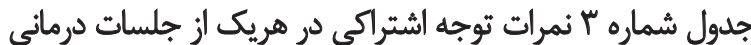
تعيين كرديد.

بر اساس جدول "ا، مشخص شد كه نمرات توجه اشتراكى در هر

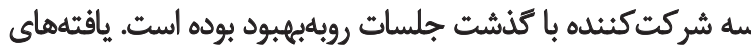

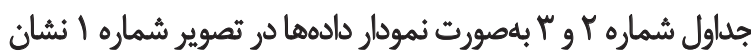
مالده شُهده أستَ.

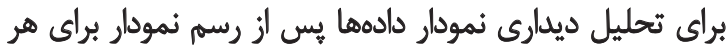

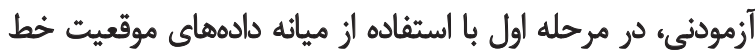

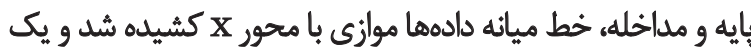

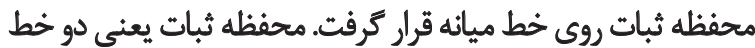

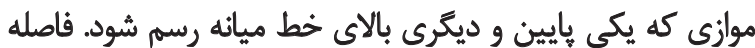

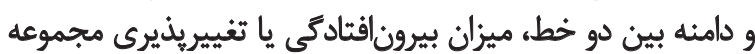

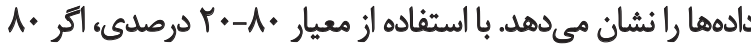

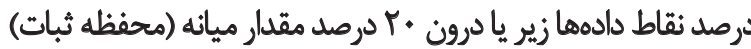

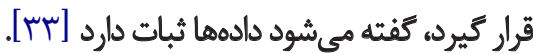
يسازآن براي بررسى روند دادهها، از روش دوئمكردن استفاده

16. Percentage of Non-overlapping Data (PND)

17. Percentage of Overlapping Data (POD)

18. Gast and Ledford

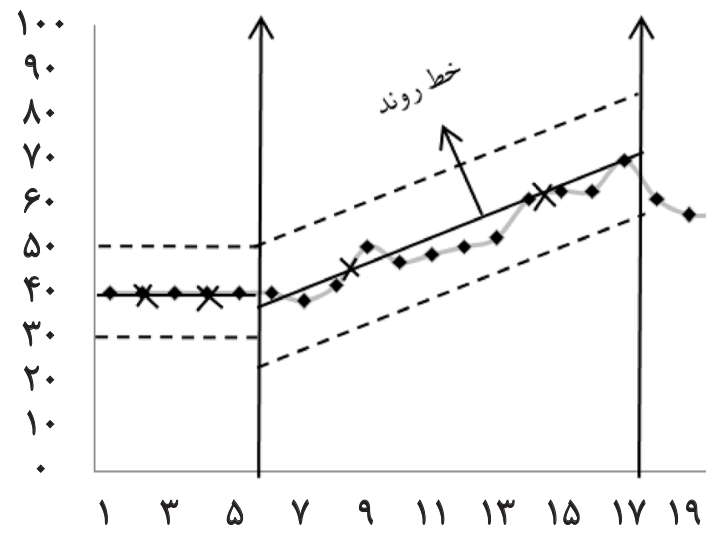

تصوير r. خط ميانه، خط روند و محفظه ثبات شركت كثنده اول. 
جدول F. متغيرهاي تحليل ديداري درونموقعيتى و بينموقعيتى براي شركت كنثده اول.

\begin{tabular}{|c|c|c|c|c|}
\hline \multicolumn{2}{|c|}{ 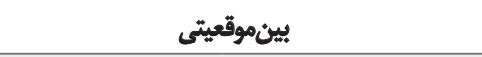 } & \multicolumn{3}{|r|}{ 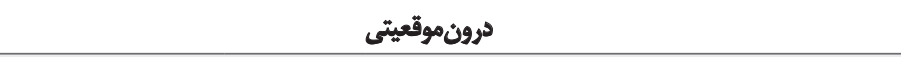 } \\
\hline$A\lfloor B$ & 1. مقايسه موقعيت & B & A & 1. توالى موقعيت \\
\hline & 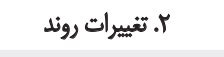 & ir & $\Delta$ & 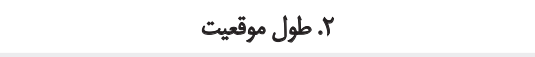 \\
\hline$\nu_{+}$ & 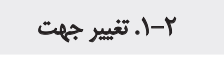 & & & 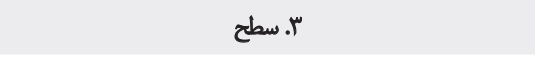 \\
\hline هثبت & ז-r. اثر وإبسته به هـف & $\Delta \cdot / \varphi$ & ra/qT & "ب-1. ميانه \\
\hline \multirow[t]{2}{*}{ باثبات به باثبات } & r-" r. تغيير ثبات & $\Delta r / . P$ & rq/qr & "ب-1.ميانكين \\
\hline & آل آ. تغيير در سطح & $s q / \pi-n / / \varphi$ & $\begin{array}{l}-r q / q r \\
\text { rq/qT }\end{array}$ & 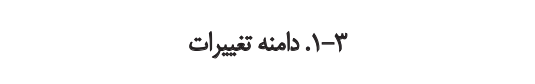 \\
\hline$m+/ r+4$ + rq/qT & 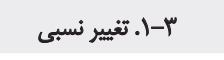 & 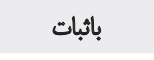 & 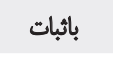 & ب-1-ا. دامنه تغييرات محفظله ثبات • ب درصد لز ميانه هر موقعيت \\
\hline rNIS de rq/ar & T-Y. تغيير مطلق & & & f. تغيير سطح \\
\hline Q./PT \& r raq & "r-" تغيير ميانه & EN/pi-AT/N. & $\begin{array}{l}\text {-rqq9 } \\
\text { rq/qY }\end{array}$ & 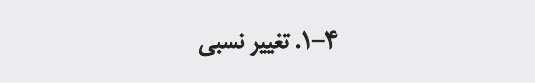 \\
\hline \multirow[t]{2}{*}{$\Delta Y /+F+r a / q T$} & با بأ. تغيير ميانكين & sq/ra-n//le & $\begin{array}{l}\text {-rq/qT } \\
\text { rV/qY }\end{array}$ & 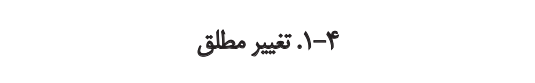 \\
\hline & f. هميوشى دادهها & & & هـــ روند \\
\hline$\Delta T / \pi T \%$ & PND .I- & مeصودى & شيب صفر & ه-1-. جهت \\
\hline $18198 \%$ & POD.I-F & باثبات & باثبات & ه-ا. ثبات \\
\hline
\end{tabular}

توانبخننى

\section{ثنايجج بلدستأمده براي شركت كثنده سوم}

براساس تحليل ديدارى نمودار دادههاى شركت كنيده سوم، خط

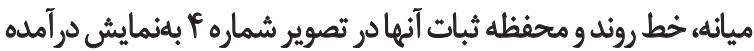
است.

جدول شماره \&، نتايج تحليل ديدارى درونموقعيتي وبينموقعيتي را براساس فرمول تحليل ديداري براي نمودار دادههاي شركت كت كنينده سومه

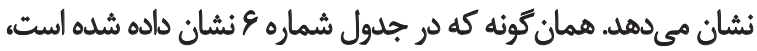

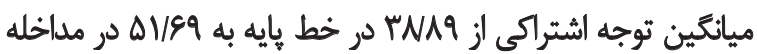

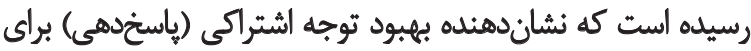

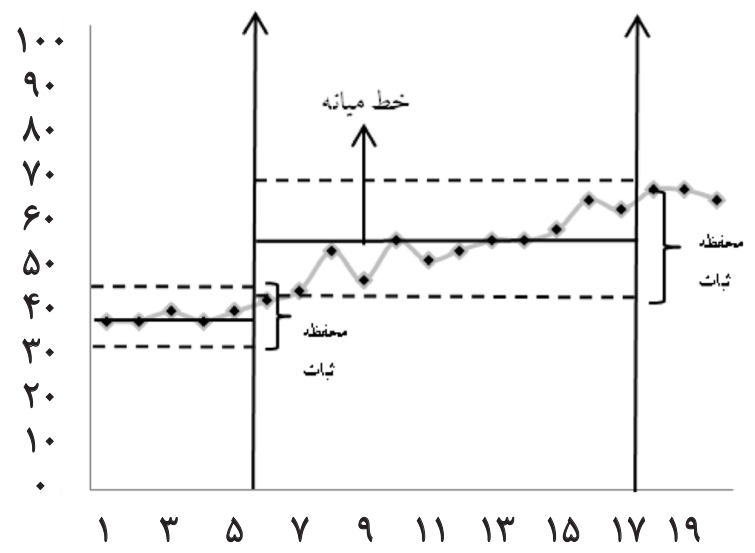

توانبخننى
بينموقعيتي رابراساس فرمول تحليل ديداري براي نمودار دادههاي

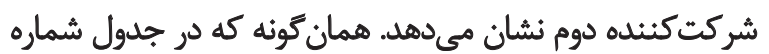

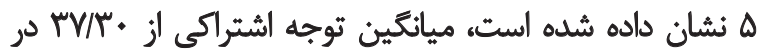

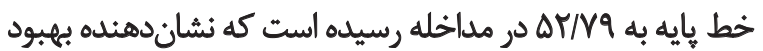
توجه اشتراكى (ياسخدهى) براى شركت كتينده موردنظر است ائه اين

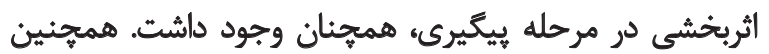

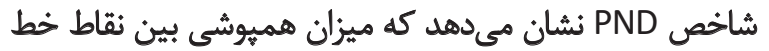

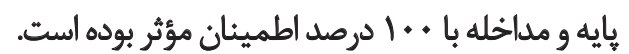

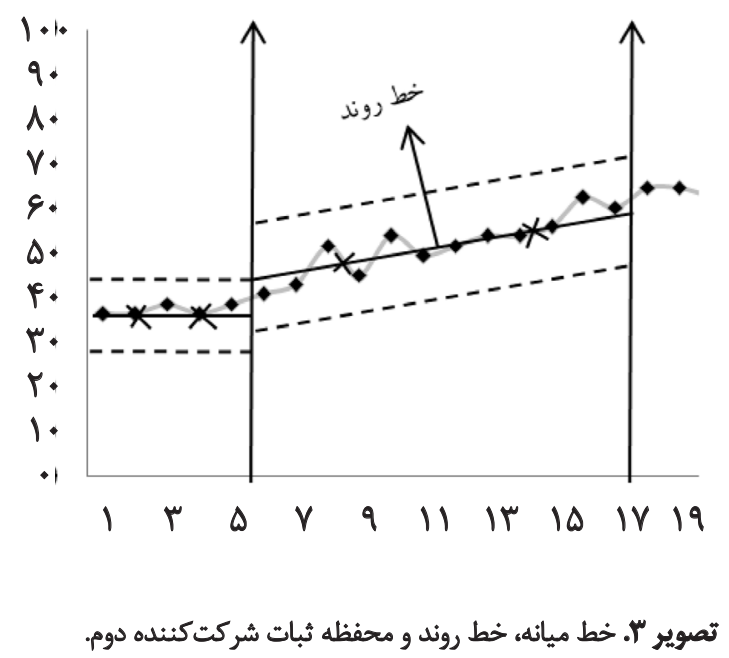


جدول ه. متغيرهاي تحليل ديدارى درونموقعيتى و بينموقعيتى براي شركت كنثده دوم.

\begin{tabular}{|c|c|c|c|c|}
\hline \multicolumn{2}{|c|}{ بينموقعيثي } & \multicolumn{3}{|r|}{ ورونموقعيتى } \\
\hline$B \bigsqcup \mathrm{A}$ & 1. مقايسه موقعيت & B & A & 1. التوالى موقعيت \\
\hline & 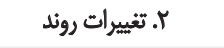 & ir & $\Delta$ & 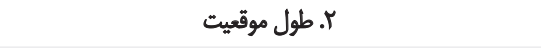 \\
\hline$V_{+}$ & r-1. تغيير جهت & & & 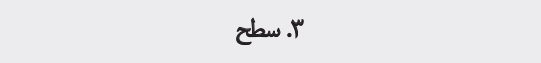 \\
\hline مثبت & 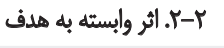 & $\Delta \mu / \Lambda_{\bullet}$ & 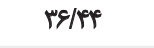 & 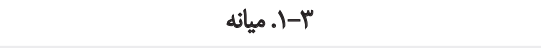 \\
\hline \multirow[t]{2}{*}{ باثبات به باثبات } & Y-Y. ت تغيير ثبات & $\Delta T / Y q$ & $\Vdash V / \mu_{*}$ & 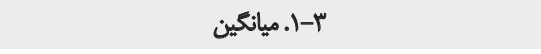 \\
\hline & 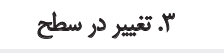 & $g T / F+-P V / V \Lambda$ & HNYS-SI/PY & 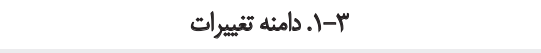 \\
\hline PV/TQ ه بNAI & 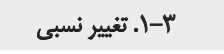 & باثبات & باثبات & r-I. دامنه تغييرات محفظه ثبات .Y درصد از ميانه هر موقعيت \\
\hline$P=N A$ C ب YNAI & 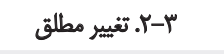 & & & |f. تغيير سطح \\
\hline 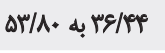 & 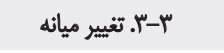 & QNPV-IT/TQ & PNME-SI/RY & 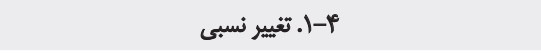 \\
\hline \multirow[t]{2}{*}{ هr/Mq ب TV/T. } & ب-أ. تعيير ميانكين & $\varepsilon \cdot / f=-r \cdot / v \Lambda$ & TNTE-SI/FF & f-1-1. تغيير هطلق \\
\hline & f. هميوشى دادهها & & & هـ روند \\
\hline $1 \cdot 0 \%$ & PND.I-r & معودى & شيب صفر & $\theta$ \\
\hline$\%$ & POD.I-r & 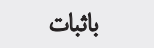 & باثبات & 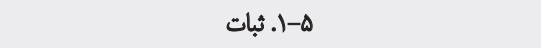 \\
\hline
\end{tabular}

توانبخننى

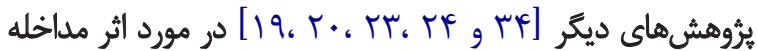

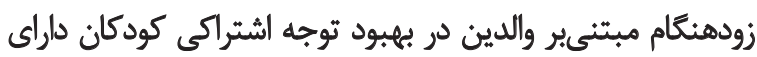
اختلال طيف اوتيسم همسو و همخوان است.

براساس تصوير شماره ا، نمرات توجه اشتراكى در هر سه

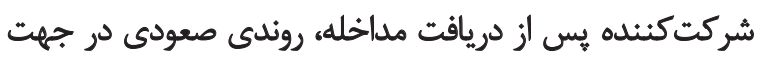

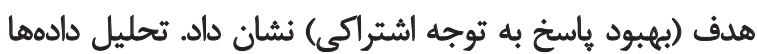

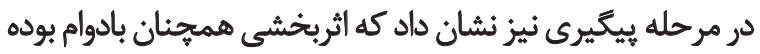

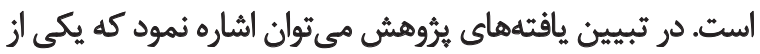

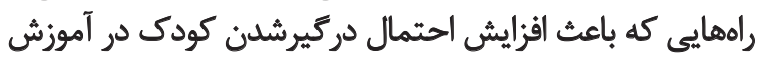

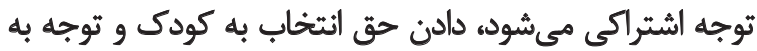

شركت كنئده موردنظر است. اين اثربخشى در مرحله يُيكيرى، همجنان

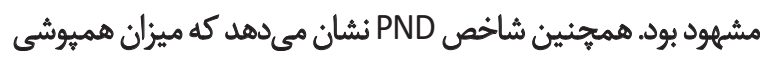
بين نقاط خط بايه و مداخله بال وأورصد اطمينان مؤثر بوده است.
يُروهش حاضر باهدف بررسى اثربخشى مداخله زودهنكام مبثنى بريبر

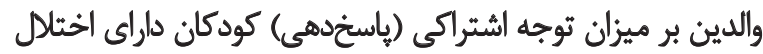

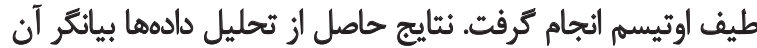

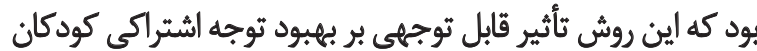

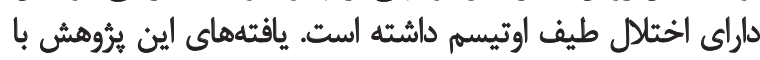

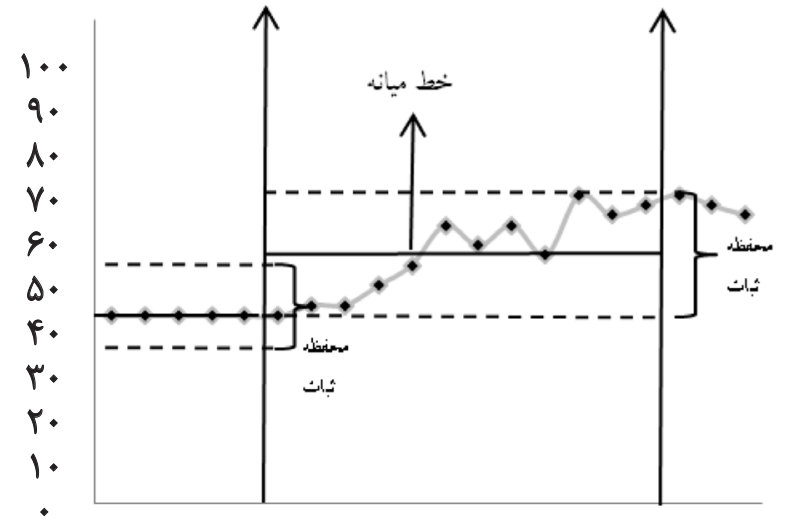

I r a r 911 ir 10 ir 19

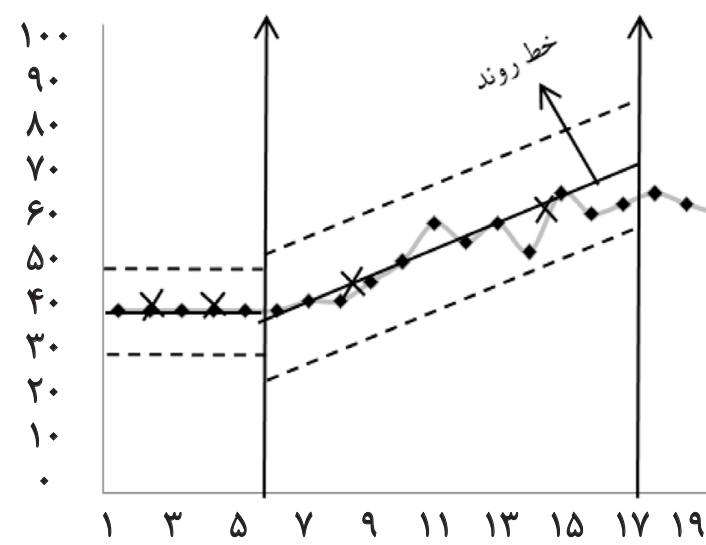

تصوير †. خط ميائه، خط روند و محفظه ثبات شركتكثنده سوم. 
جدول و. متغيرهاى تحليل ديدارى درونموقعيتى و بينموقعيتى براى شركتكثنده سوم.

\begin{tabular}{|c|c|c|c|c|}
\hline \multicolumn{2}{|c|}{ بينموقعيتى } & \multicolumn{3}{|r|}{ دورنموقعيتى } \\
\hline$A \biguplus B$ & ا. مقايسه موقعيت & B & A & ا. توالى موقعيث \\
\hline & 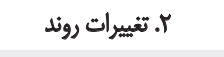 & ir & $\Delta$ & 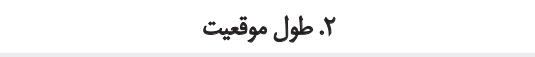 \\
\hline+ & r - 1-1. تغيير جهت & & & 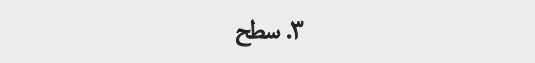 \\
\hline مثبت & ז-Y. اثر وابسته به هدف & $\Delta T / F$ & rNA9 & "Y-1. ميائه \\
\hline \multirow[t]{2}{*}{ باثبات به باثبات } & Y-"'. تغيير ثبات & $\Delta V / g q$ & rNA9 & "r-1. ميانكين \\
\hline & ب. - م. تغيير در سطح & RT/TA-AV/A & HNTA-AVA & 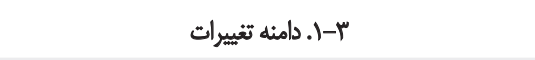 \\
\hline RT/.F ب بNAq & 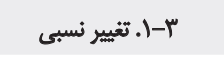 & باثبات & باثبات & r-1- دامنه تغييرات هحفظه ثبات ·r درصد از ميانه هر موقعيت \\
\hline rNAq ب rNAq & 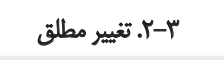 & & & (f. - تغيير سطح \\
\hline$\Delta T / m q$ ه ب rNAq & 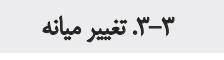 & $\Delta N F T-Q T / \cdot F$ & "NMA-AVAq & 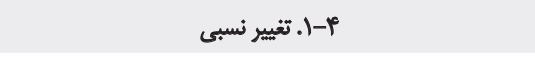 \\
\hline \multirow[t]{2}{*}{ DV/R9 ب بNAq } & س-أ. تغيير ميانكين & RI/TA-nT/Aq & WNTA-AVAq & 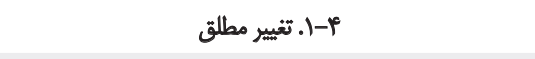 \\
\hline & 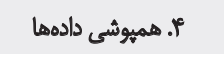 & & & 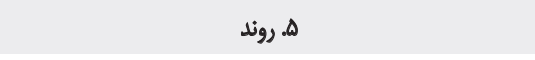 \\
\hline $91 / 88 \%$ & PND.1-r & 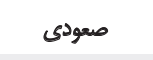 & 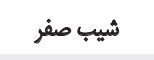 & ه-1. جهت \\
\hline$N M F \%$ & POD.I-F & باثبات & باثبات & ه-1. ثبات \\
\hline
\end{tabular}

توانبخنتى

در يروهش حاضر تبيين ديكًر براى بهبود هاسخ به به توجه

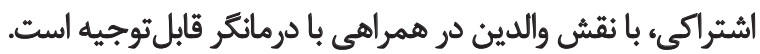

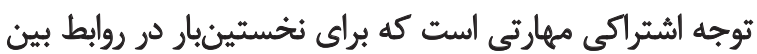

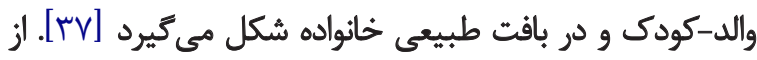

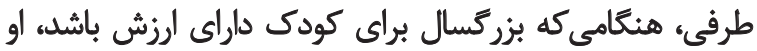

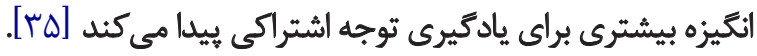

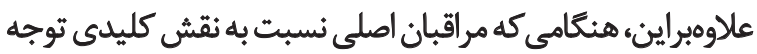

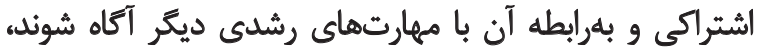

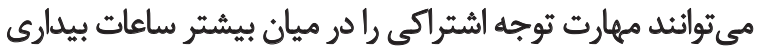

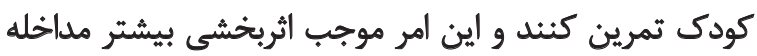

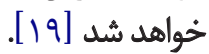

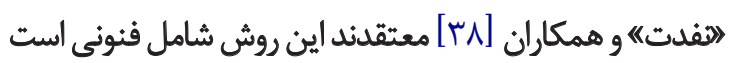

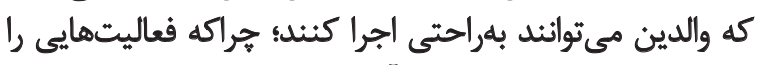

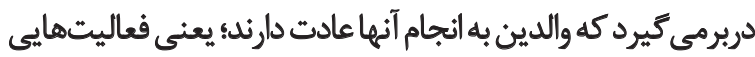

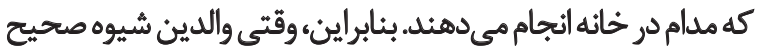

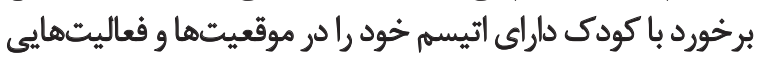

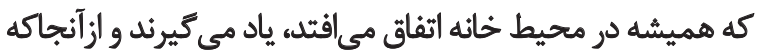

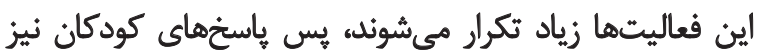

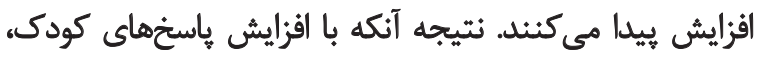

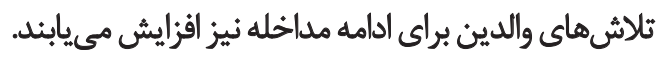

\section{نتيجليَيرى}

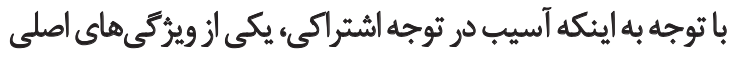

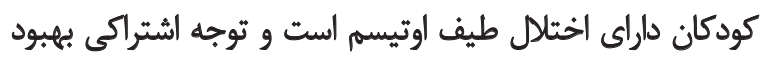

عواملى است كه كودى آنها را ترجيح مى دهد [مَ]. يُؤوهشكران معتقدند هنكامى كه قصد آموزش توجه اشتراكى رابه

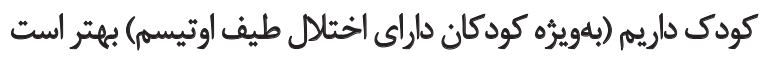

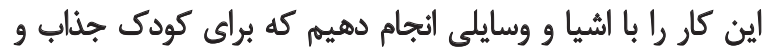

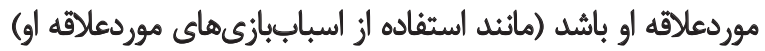

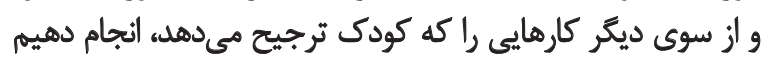

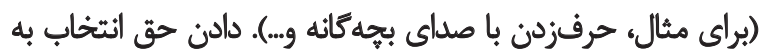

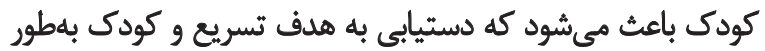

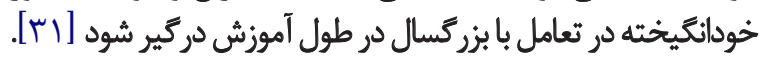
تبيين ديكر به نقش تقويت كنندههاى طبيعى در اين مداخله

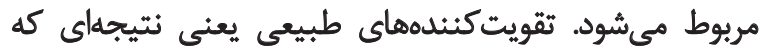

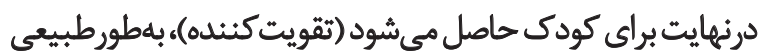

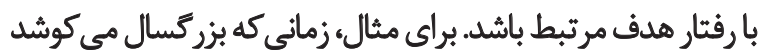

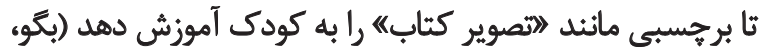

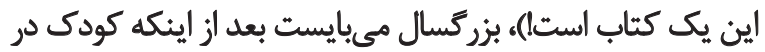

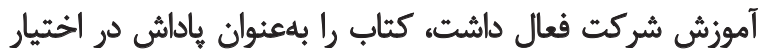

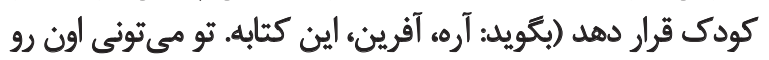

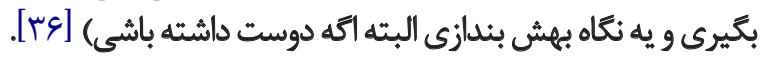

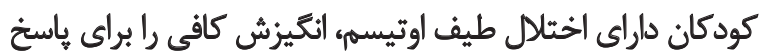

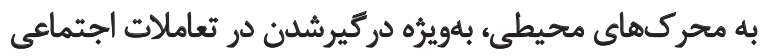

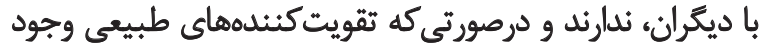

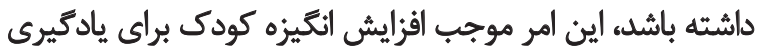
هاسخ به توجه اشتراكى مىشود [ابـ] 


\section{References}

[1] Al-Khalaf A, Dempsey I, Dally K. The Effect of an Education Program for Mothers of Children with Autism Spectrum Disorder in Jordan. International Journal for the Advancement of Counselling. 2014; 36(2):175-87.

[2] Posar A, Resca F, Visconti P. Autism according to diagnostic and statistical manual of mental disorders $5^{\text {th }}$ edition: The need for further improvements. Journal of Pediatric Neurosciences. 2015; 10(2):146.

[3] Mandell D, Lecavalier L. Should we believe the Centers for Disease Control and Prevention's autism spectrum disorder prevalence estimates? Autism. 2014; 18(5):482-4.

[4] Samadi SA, McConkey R. Screening for Autism in Iranian Preschoolers: Contrasting M-CHAT and a Scale Developed in Iran. Journal of Autism and Developmental Disorders. 2015; 45(4):1-9.

[5] Kasari C, Freeman SFN, Paparella T. Early intervention in autism: Joint attention and symbolic play. International Review of Research in Mental Retardation. 2000; 23(1):207-37.

[6] Lieberman AM, Hatrak M, Mayberry RI. Learning to look for language: Development of joint attention in young deaf children. Language Learning and Development. 2014; 10(1):19-35.

[7] Kasari C, Gulsrud AC, Wong C, Kwon S, Locke J. Randomized controlled caregiver mediated joint engagement intervention for toddlers with autism. Journal of Autism and Developmental Disorders. 2010; 40(9):1045-56.

[8] Mundy P, Sullivan L, Mastergeorge AM. A parallel and distributed-processing model of joint attention, social cognition and autism. Autism Research. 2009; 2(1):2-21.

[9] Osterling J, Dawson G. Early recognition of children with autism: A study of first birthday home videotapes. Journal of Autism and Developmental Disorders. 1994; 24(3):247-57.

[10] van Hecke AV, Mundy P, Block JJ, Delgado CEF, Parlade MV, Pomares YB, et al. Infant responding to joint attention, executive processes, and self-regulation in preschool children. Infant Behavior and Development. 2012; 35(2):303-11.

[11] Murray DS, Creaghead NA, Manning-Courtney P, Shear PK, Bean J, Prendeville JA. The relationship between joint attention and language in children with autism spectrum disorders. Focus on Autism and Other Developmental Disabilities. 2008; 23(1):514.

[12] Watt N, Wetherby A, Shumway S. Prelinguistic predictors of language outcome at 3 years of age. Journal of Speech, Language, and Hearing Research. 2006; 49(6):1224-37.

[13] Mundy P, Sigman M, Kasari C. Joint attention, developmental level, and symptom presentation in autism. Development and Psychopathology. 1994; 6(3):389-401.

[14] Naber FB, Bakermans Kranenburg MJ, van Ijzendoorn MH, Dietz C, van Daalen E, Swinkels SH, et al. Joint attention development in toddlers with autism. European Child \& Adolescent Psychiatry. 2008; 17(3):143-52.
در ديكّر حيطههاي رشدى را بههمراه دارد، هى توان بيشنهاد كرد

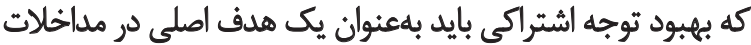
توانبخشى و آموزشى در كودكان داراى اختلال طيف إنيف اوتيسم تعيين

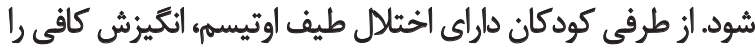

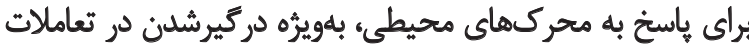

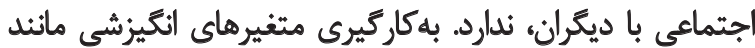

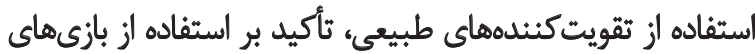

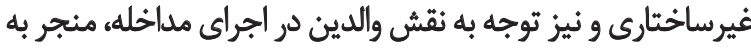

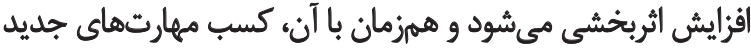
نيز باسرعت بيشترى صورت مي ميذيرد.

يافتههاى اين يرؤهش از آن جهت كه توانست رويكرد جديدى در

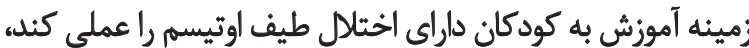

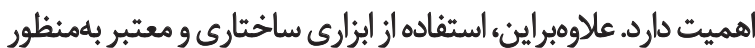

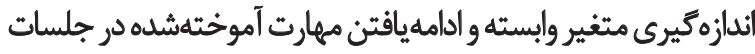

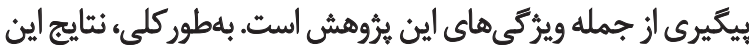

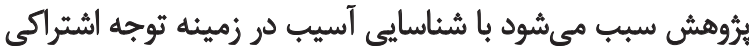

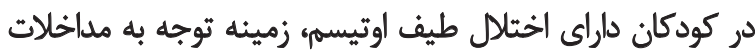
آموزشى و توانبخشى زودهنكام فرانما لهم شود.

از محدوديتهاي اين يُروهش مى توان به محدوديت سنى، مشكل

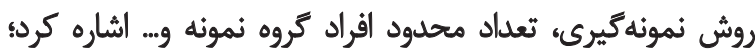

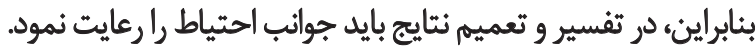

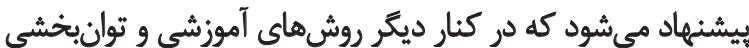

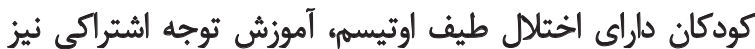

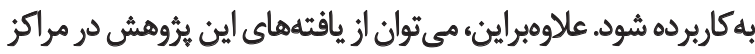
مشاوره و توانيخشى استفاده نمود.

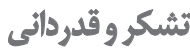

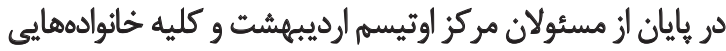

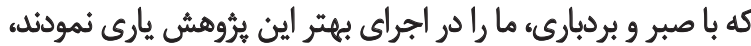
كمال تشكر وقدردانى بهعمل مي مآيد. 
[15] Mundy P. Joint attention and social-emotional approach behavior in children with autism. Development and Psychopathology. 1995; 7(01):63-82.

[16] Striano T, Chen X, Cleveland A, Bradshaw S. Joint attention social cues influence infant learning. European Journal of Developmental Psychology. 2006; 3(3):289-99.

[17] Mundy P, Block J, Delgado C, Pomares Y, van Hecke AV, Parlade MV. Individual differences and the development of joint attention in infancy. Child Development. 2007; 78(3):938-54.

[18] Alliston L. Principles and practices in Early Intervention: A literature review for the Ministry of Health. Wellington, New Zealand: Ministry of Health; 2007.

[19] Schertz HH, Odom SL. Promoting joint attention in toddlers with autism: A parent-mediated developmental model. Journal of Autism and Developmental Disorders. 2007; 37(8):1562-75.

[20] Schertz HH, Odom SL, Baggett KM, Sideris JH. Effects of Joint Attention Mediated Learning for toddlers with autism spectrum disorders: An initial randomized controlled study. Early Childhood Research Quarterly. 2013; 28(2):249-58.

[21] Ruble LA, Akshoomoff N. Autism spectrum disorders: Intervention options for parents and educators. Communiqué Handout. 2010; 38(5):1-6.

[22] Sandall S, McLean ME, Smith BJ. DEC recommended practices in early intervention/early childhood special education. Longmont, Co: Sopris West; 2000.

[23] Vo A. Joint Attention Interventions for Young Children with Autism Spectrum Disorders: Caregiver and Child Actions and Transactions [PhD Thesis]. Virginia, USA: Virginia Commonwealth University Press; 2011.

[24] Schulz RA. Joint Attention Intervention with Assisting Parent Mediated Techniques to Increase a Toddler with Autism Spectrum Disorders' Use of Joint Attention: A Single Case Study [MA Thesis]. Mankato, United States: Minnesota State University; 2015.

[25] Gilliam JE. Gilliam Autism Rating Scale: Examiner’s Manual. Austin, TX: Pro-Ed; 1995.

[26] Ahmadi S, Safari T, Hemmatian M, Khalili Z. [The psychometric properties of Gilliam autism rating scale (Persian)]. Researches of Cognitive and Behavioral Science. 2011; 1(1):87-104.

[27] Mundy P, Delgado C, Block J, Venezia M, Hogan A, Seibert J. Early social communication scales (ESCS). Coral Gables, Florida: University of Miami; 2003.

[28] Laing E, Laing E, Longhi A. Atypical development of language and social communication in toddlers with Williams syndrome. Developmental Science. 2002; 5(2):233-46.

[29] Asghari Nekah SM, Afrooz GA, Bazargan A, Shokoohi Yekta M. [The effect of puppet play therapy intervention on communicative skills of autistic children (Persian)]. Journal of Fundamentals of Mental Health. 2011; 13(1):42-57.

[30] Dawson G, Meltzoff AN, Osterling J, Rinaldi J, Brown E. Children with autism fail to orient to naturally occurring social stimuli. Journal of Autism and Developmental Disorders. 1998; 28(6):479-85.
[31] Whalen C, Schreibman L, Ingersoll B. The collateral effects of joint attention training on social initiations, positive affect, imitation, and spontaneous speech for young children with autism. Journal of Autism and Developmental Disorders. 2006; 36(5):655-64.

[32] Whalen C, Schreibman L. Joint attention training for children with autism using behavior modification procedures. Journal of Child Psychology and Psychiatry. 2003; 44(3):456-68.

[33] Gast DL, Ledford JR. Single-subject research methodology in behavioral sciences. New York: Routledge Press; 2009.

[34] Jones EA, Carr EG, Feeley KM. Multiple effects of joint attention intervention for children with autism. Behavior Modification. 2006; 30(6):782-834.

[35] Jones EA, Carr EG. Joint Attention in Children with Autism Theory and Intervention. Focus on Autism and Other Developmental Disabilities. 2004; 19(1):13-26.

[36] Koegel RL, Koegel LK. The PRT Pocket Guide: Pivotal Response Treatment for Autism Spectrum Disorders. Baltimore: Brookes Publishing Company; 2012.

[37] Meins E, Fernyhough C, Arnott B, Vittorini L, Turner M, Leekam SR, et al. Individual differences in infants' joint attention behaviors with mother and a new social partner. Infancy. 2011; 16(6):587-610.

[38] Nefdt N, Koegel R, Singer G, Gerber M. The use of a self-directed learning program to provide introductory training in pivotal response treatment to parents of children with autism. Journal of Positive Behavior Interventions. 2010; 12(1):23-32. 